\title{
ChemComm
}

\section{Surprising acidity of hydrated lithium cations in organic solvents $\dagger$}

Cite this: Chem. Commun., 2014 50,5554

Received 13th March 2014, Accepted 3rd April 2014

DOI: $10.1039 / c 4 c c 01892 c$

www.rsc.org/chemcomm

\author{
Haiqiang Deng, ${ }^{a}$ Pekka Peljo, ${ }^{\mathrm{ab}} \mathrm{T}$. Jane Stockmann, ${ }^{\mathrm{a}}$ Liang Qiao, ${ }^{\mathrm{a}}$ Tuomas Vainikka, \\ Kyösti Kontturi, ${ }^{b}$ Marcin Opallo ${ }^{c}$ and Hubert H. Girault*a
}

\begin{abstract}
Lithium cations are shown to have a significant role in catalyzing oxygen and proton reduction along with $\mathrm{S}_{\mathrm{N}} 1$ reactions in biphasic systems. We propose that this catalytic effect is due to the surprising acidity of the hydrated cations; interactions between the cation and its surrounding solvation shell will make the constituent water molecules more acidic.
\end{abstract}

Cation hydrolysis reactions, where a hydrated metal cation acts as a Brønsted acid giving the corresponding metal hydroxide complex and a proton, are well-known reactions in aqueous solutions. ${ }^{1-3}$ It is also well known that many lanthanide and transition metal salts can be employed as Lewis acids to catalyze organic reactions; the catalytic activity has been found to correlate with the hydrolysis constant and the water exchange rate constant. ${ }^{4}$ However, hydrolysis of lithium cations can also have a significant influence on reactions in biphasic systems. This communication describes the effect of lithium hydrolysis in organic solvents for the catalysis of oxygen and proton reduction by decamethylferrocene (DMFc), as well as for catalysis of a $S_{\mathrm{N}} 1$ reaction.

In nature, oxygen reduction takes place at the hydrophobic lipid bilayer of the mitochondrial membrane; this includes transfer of protons and electrons between the hydrophobic lipid bilayer and the adjacent aqueous phases. ${ }^{5,6}$ The interface between two immiscible electrolyte solutions (ITIES) offers a biomimetic but simplified platform to study these reactions. ${ }^{7}$ Electrochemistry at ITIES enables the monitoring of ion and electron transfers across the interface, ${ }^{8}$ which are the elementary processes in cellular traffic. Hence, it has been used to study both oxygen reduction $(\mathrm{ORR})^{9-18}$ and hydrogen evolution (HER) $)^{19-22}$ reactions by molecular electron donors at ITIES. ${ }^{23}$

\footnotetext{
${ }^{a}$ Laboratoire d'Electrochimie Physique et Analytique, Ecole Polytechnique Fédérale de Lausanne (EPFL), Station 6, CH-1015 Lausanne, Switzerland. E-mail: hubert.girault@epfl.ch

${ }^{b}$ Department of Chemistry, Aalto University, P.O. Box 16100, 00076 Aalto, Finland ${ }^{c}$ Institute of Physical Chemistry, Polish Academy of Sciences, ul. Kasprazaka 44/52, 01-224 Warszawa, Poland

$\dagger$ Electronic supplementary information (ESI) available: Experimental details, more detailed ESI-MS spectra, additional results from two-phase shake flask reactions, and thermodynamic calculations. See DOI: 10.1039/c4cc01892c
}

Both of these reactions can be easily performed in the presence of a suitable molecular electron donor by pumping the protons into the organic phase. ${ }^{23}$ This could be done either by using a potentiostat or by addition of a phase transfer catalyst, e.g. lithium tetrakis(pentafluorophenyl) borate (LiTB), into an acidic aqueous phase. ${ }^{11,21,23}$ As the $\mathrm{TB}^{-}$anion is very lipophilic, ${ }^{24}$ it transfers into the organic phase with an equal amount of protons or lithium ions to maintain the electroneutrality. The proton transfer from aqueous into the organic phase can also be catalysed by addition of a suitable base, like different anilines ${ }^{25,26}$ or free-base porphyrins, ${ }^{16,27}$ in the organic phase. In this communication, the effect of the cation hydrolysis in the organic phase on the oxygen/proton reduction by a molecular electron donor, DMFc, is described. This effect is then extended to a $\mathrm{S}_{\mathrm{N}} 1$ reaction, demonstrating that lithium cations can be used as Brønsted acids in acid catalyzed reactions.

Biphasic oxygen reduction by DMFc was studied in so called shake flask experiments, where an organic phase (1,2-dichloroethane, DCE) containing DMFc was mixed with an equal volume of aqueous phase. The mixtures shown in Fig. 1 were stirred rigorously for $140 \mathrm{~min}$ and subsequently analyzed using UV-vis spectroscopy as well as electrochemically by voltammetry using a glassy carbon microelectrode.

A solution of DMFc in DCE has a yellow color with an absorption peak at $425 \mathrm{~nm}$; however, when DMFc is oxidized to $\mathrm{DMFc}^{+}$, the solution turns green and the UV-vis spectrum has a peak at $779 \mathrm{~nm}$. When the DCE phase contained LiTB, both voltammetry and UV-vis spectroscopy indicate that a significant amount of DMFc was oxidized (Fig. 2). Only minimal changes were observed in the control experiments without LiTB (Fig. 1E, see ESI $\dagger$ ). If the reaction with LiTB was repeated in an anaerobic atmosphere, almost no changes were observed. This confirms that DMFc is oxidized by oxygen, and the presence of $\mathrm{Li}^{+}$cations in the organic phase is essential for oxygen reduction to take place.

The $\mathrm{pH}$ of the aqueous phase increased from 6.80 to 9.95, indicating that ca. $0.1 \mathrm{mM}$ of $\mathrm{OH}^{-}$was produced; however, no hydrogen peroxide was observed in the aqueous phase by the NaI method. ${ }^{28}$ Hence the total reaction can be described as 




Fig. 1 The $1 \mathrm{mM}$ DMFc solution and the different shake flask experiments after 140 min of reaction.
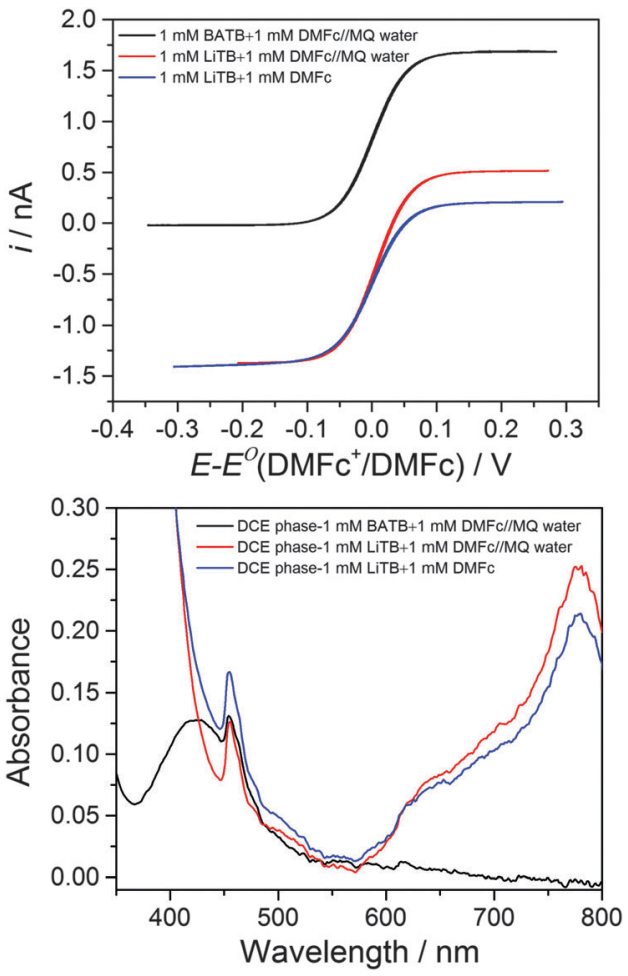

Fig. 2 Microelectrode voltammogram and UV-vis spectra of the organic phase before and after the reactions.

$$
\mathrm{O}_{2}+2 \mathrm{H}_{2} \mathrm{O}+2 \mathrm{DMFc} \rightarrow 2 \mathrm{DMFc}^{+}+\mathrm{H}_{2} \mathrm{O}_{2}+2 \mathrm{OH}^{-}
$$

followed by either the further reduction reaction ${ }^{11,13,29}$

$$
\mathrm{H}_{2} \mathrm{O}_{2}+2 \mathrm{DMFc} \rightarrow 2 \mathrm{DMFc}^{+}+2 \mathrm{OH}^{-}
$$

or the decomposition reaction ${ }^{11,13}$

$$
2 \mathrm{H}_{2} \mathrm{O}_{2} \rightarrow 2 \mathrm{H}_{2} \mathrm{O}+\mathrm{O}_{2}
$$

The $\mathrm{p} K_{\mathrm{a}}$ of $\mathrm{H}_{2} \mathrm{O}_{2}$ is $11.62 ;^{30}$ therefore, below this $\mathrm{pH}$ hydrogen peroxide is mostly in a protonated form.

Curiously, flask “B” containing only DMFc and LiTB in DCE, without any added water, also turned green during the reaction. However, the water content of a commercial DCE solvent used in the experiments was determined to be $26 \mathrm{mM}$ by the Karl-Fischer method. This indicates that the amount of residual water in the solvent is enough for oxygen reduction to take place.

In the presence of protons, oxygen reduction by DMFc is thought to proceed by protonation of the electron donor at the iron core, forming the activated hydride $[\mathrm{DMFc}-\mathrm{H}]^{+} .^{31}$ Subsequently, the molecular oxygen dissolved in the bulk DCE binds to the $[\mathrm{DMFc}-\mathrm{H}]^{+}$via a delocalized triplet transition state $[\mathrm{DMFc} \cdots \mathrm{H} \cdots \mathrm{OO}]^{+}$, finally resulting in the oxidation of DMFc to form $\mathrm{DMFc}^{+}$and the generation of hydrogen peroxyl radical species $\mathrm{HO}_{2} \bullet{ }^{31}$ The $\mathrm{HO}_{2}{ }^{\bullet}$ will then react rapidly with another DMFc and proton to form $\mathrm{H}_{2} \mathrm{O}_{2} \cdot{ }^{16,32,33}$

Oxygen reduction also takes place in the absence of protons, but only in the presence of LiTB. If LiTB was replaced with BATB, no changes were observed (Fig. 1E). It has been shown that small alkali metal cations like $\mathrm{Li}^{+}$and $\mathrm{Na}^{+}$transfer into the organic phase along with their hydration shell; however, hydrophobic cations like $\mathrm{BA}^{+}$shed the hydration shell and are instead solvated predominately by DCE molecules. ${ }^{34-36}$ These results indicate that highly hydrophilic cations, surrounded by a hydration shell, are essential components for catalyzing oxygen reduction in an organic phase. Hence, we can propose that interactions between the positively charged ion and the water molecules in the surrounding hydration layer make the protons more acidic. This is a well-known property of metal ions in solution; for example, many metal ions with higher charges, like aluminium(III) or zinc(II), are strong enough to dissociate water. ${ }^{1-3} \mathrm{Li}^{+}$has a $\mathrm{p} K_{\mathrm{a}}$ of $13.8 .^{30}$

Most likely the mechanism is that the hydrolysis of cation allows the formation of the $[\mathrm{DMFc}-\mathrm{H}]^{+}$, and the oxygen reduction can proceed similarly as in the presence of protons.

$$
\begin{gathered}
{\left[\mathrm{Li}\left(\mathrm{H}_{2} \mathrm{O}\right)_{n}\right]^{+}+\mathrm{DMFc} \rightarrow\left[\operatorname{LiOH}\left(\mathrm{H}_{2} \mathrm{O}\right)_{n-1}\right]+[\mathrm{DMFc}-\mathrm{H}]^{+}} \\
{[\mathrm{DMFc}-\mathrm{H}]^{+}+\mathrm{O}_{2} \rightarrow\left[\mathrm{DMFc} \cdots \mathrm{H} \cdots \mathrm{O}_{2}\right] \rightarrow \mathrm{DMFc}^{+}+\mathrm{HO}_{2}^{\bullet}} \\
\mathrm{HO}_{2}^{\bullet}+\mathrm{DMFc}+\left[\mathrm{Li}\left(\mathrm{H}_{2} \mathrm{O}\right)_{n}\right]^{+} \rightarrow \mathrm{H}_{2} \mathrm{O}_{2}+\mathrm{DMFc}^{+}+\left[\mathrm{LiOH}\left(\mathrm{H}_{2} \mathrm{O}\right)_{n-1}\right]
\end{gathered}
$$

All the reactions (4)-(6) take place in the DCE phase; however, in the presence of water, the produced $\mathrm{LiOH}$ and $\mathrm{H}_{2} \mathrm{O}_{2}$ will transfer into the aqueous phase. In the absence of water $\mathrm{LiOH}$ will precipitate as it is not soluble in DCE (for calculation of the solubility product, see ESI $\dagger$ ). The total Gibbs energy for reactions (4)-(6), when LiOH is transferred into the aqueous phase, is $-111 \mathrm{~kJ} \mathrm{~mol}^{-1}$ and $-78.9 \mathrm{~kJ} \mathrm{~mol}^{-1}$ for the case where LiOH precipitates in the DCE phase; therefore, both reactions are clearly thermodynamically favorable. The Gibbs free energy in the absence of $\mathrm{Li}^{+}$in the organic phase is $+57.3 \mathrm{~kJ} \mathrm{~mol}^{-1}$ (see ESI $\dagger$ ); these calculations confirm that the presence of $\mathrm{Li}^{+}$is essential for these reactions to proceed. 


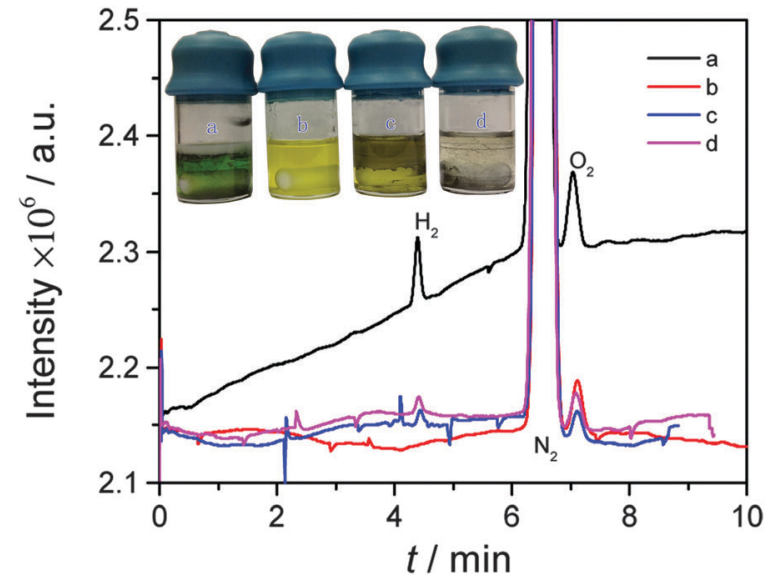

Fig. 3 Gas chromatograms of the headspaces for shake-flask reactions after $16 \mathrm{~h}$ stirring under anaerobic conditions. Inset shows the corresponding photographs of the shake-flask glass vials after reaction. (a) $10 \mathrm{mM} \mathrm{DMFc}+$ 10 mM LiTB with $\mathrm{Mo}_{2} \mathrm{C}$. (b) No LiTB and catalyst, (c) no LiTB, (d) no DMFc.

The same system was tested under anaerobic conditions. If a well-known catalyst $\mathrm{Mo}_{2} \mathrm{C}^{20}$ was added to the mixture $\left(1.7 \mathrm{~g} \mathrm{~L}^{-1}\right)$, very small amounts of hydrogen was detected after the shake flask reaction with $10 \mathrm{mM}$ DMFc and LiTB in the DCE phase after $16 \mathrm{~h}$ of reaction (Fig. 3). This confirms that cation facilitated water hydrolysis can provide a source of protons for oxygen reduction and hydrogen evolution in the organic phase. The blank experiments without LiTB and catalyst (b), without LiTB (c), and without DMFc (d) did not show any traces of hydrogen.

Further confirmation of the significance of cation catalyzed hydrolysis in organic solvents was obtained by using LiTB in the $S_{\mathrm{N}} 1$ substitution of an indole to ferrocene methanol $(\mathrm{FcMeOH}){ }^{37}$ This demonstrates that lithium cations can be used as Brønsted acids to catalyze what are typically acid catalyzed reactions. This reaction happens fast in the presence of HTB at room temperature; ${ }^{37}$ however, when equal amounts of LiTB, indole and ferrocene methanol in DCE were left to react for $30 \mathrm{~min}$ at $60{ }^{\circ} \mathrm{C}$, the reaction product could be detected by electrospray ionization mass spectrometry (ESI-MS) at $\mathrm{m} / \mathrm{z}=$ 315 (Fig. 4). For more detailed ESI-MS spectra, see ESI. $\dagger$ This reaction was slow at room temperature.

Fig. 4 shows that the sample containing only $\mathrm{FcMeOH}$ and indole has the peaks corresponding to the protonated indole $(m / z=118)$, carbocation $\mathrm{FcCH}_{2}{ }^{+}(m / z=199)$, $\mathrm{FcMeOH}^{+}(m / z=$ 216) and small amounts of ferrocene carboxylic acid $\mathrm{FcCOOH}^{+}$ $(m / z=230)$, while the corresponding spectra of the solution containing LiTB show a significant increase of the peaks of the reaction product with indole (3-(ferrocenylmethyl)- $1 H$-indole, $m / z=315$ ) and $\mathrm{FcCOOH}^{+}$. Also, the peak for $\mathrm{FcMeOH}$ is almost absent.

As discussed previously, ${ }^{37}$ stable $\alpha$-ferrocenyl carbocations can be generated from ferrocenyl alcohols in the presence of acids. These carbocations can then react with oxygen to produce FcCOOH, or with indole. The results indicate that both of these reactions can proceed in the absence of acids at elevated temperatures, but even mild acids like $\mathrm{Li}^{+}$can significantly increase the reaction rate. However, better selectivity is obtained by proton catalysis, as in that case no $\mathrm{FcCOOH}$ was observed. ${ }^{37}$
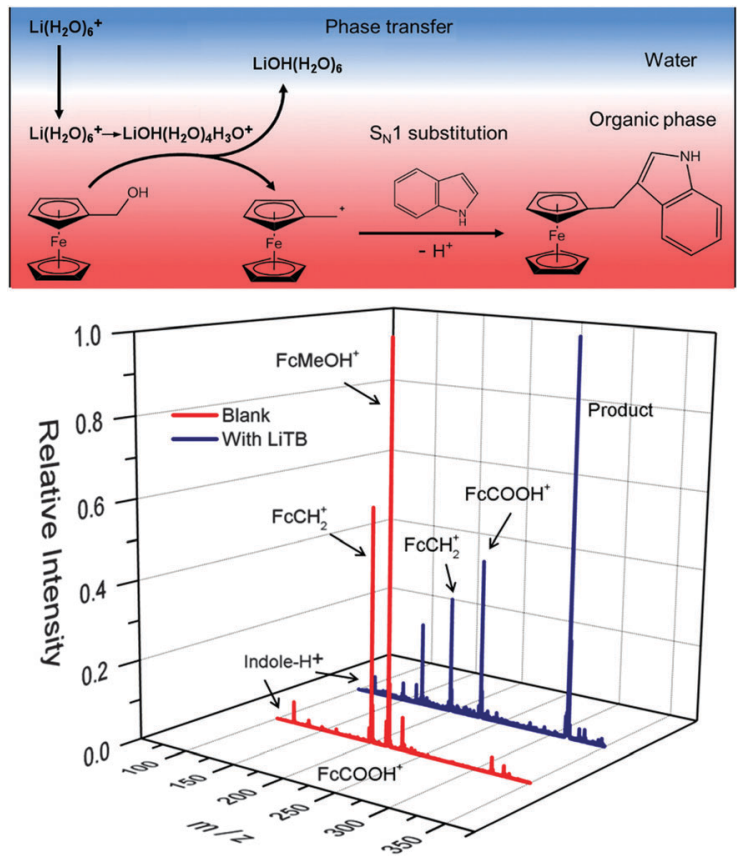

Fig. 4 The comparison of the ESI-MS spectra of the blank (5 mM FcMeOH and indole in DCE) and the LiTB catalyzed reaction $(3.33 \mathrm{mM} \mathrm{FCMeOH}$, indole and LiTB in DCE), both after 30 min reaction at $60{ }^{\circ} \mathrm{C}$. Indole- $\mathrm{H}^{+}$, protonated iodole ion; $\mathrm{FCCH}_{2}{ }^{+}, \alpha$-ferrocenyl carbocation; $\mathrm{FCMeOH}^{+}$, oxidized $\mathrm{FCMeOH}$ ion with $\mathrm{Fe}^{3+} ; \mathrm{FcCOOH}^{+}$, oxidized $\mathrm{FcCOOH}$ ion with $\mathrm{Fe}^{3+}$.

The experiments show that oxygen reduction by DMFc can take place in the absence of acids, as hydrolysis of alkali metal cations in the organic phase will provide protons for the reaction. Hydrophilic cations polarize the water molecules in their solvation shell, making the protons more acidic. These slightly acidic protons can be utilized in both oxygen reduction and hydrogen evolution by DMFc, as well as Brønsted acids as catalysts of organic reactions. This new type of catalysis based on mildly acidic protons in the solvation shell of metal cations would be useful for acid catalyzed reactions, for example, in organic synthesis.

This research was supported by Polish-Swiss Research Programme, Project PSPB-035/2010: "Electrocatalysis at droplets". H.D. acknowledges the China Scholarship Council (CSC) for financial support. The authors are also thankful to Dr Chenyi Yi (LPI, EPFL), Dr Prof. Bin Su (Zhejiang University, China), and Ms Veronique Amstutz (LEPA, EPFL) for valuable discussions and technical support.

\section{Notes and references}

1 C. F. Baes and R. E. Mesmer, The Hydrolysis of Cations, Wiley Interscience, New York, 1976.

2 J. Burgess, Metal Ions in Solution, Ellis Horwood, Chichester, 1978.

3 D. W. Barnum, Inorg. Chem., 1983, 22, 2297-2305.

4 S. Kobayashi and K. Manabe, Acc. Chem. Res., 2002, 35, 209-217.

5 P. Mitchell, Nature, 1961, 191, 144-148.

6 D. A. Proshlyakov, M. A. Pressler, C. DeMaso, J. F. Leykam, D. L. DeWitt and G. T. Babcock, Science, 2000, 290, 1588-1591.

7 H. H. Girault and D. J. Schiffrin, in Electroanalytical Chemistry. A series of advances, ed. A. J. Bard, Marcel Dekker, New York, 1989, vol. 15, p. 1.

8 P. Peljo and H. H. Girault, Encyclopedia of Analytical Chemistry, John Wiley \& Sons, Ltd, Chichester, 2012. 
9 H. Ohde, K. Maeda, Y. Yoshida and S. Kihara, J. Electroanal. Chem., 2000, 483, 108-116.

10 A. J. Olaya, P. Ge, J. F. Gonthier, P. Pechy, C. Corminboeuf and H. H. Girault, J. Am. Chem. Soc., 2011, 133, 12115-12123.

11 P. Peljo, L. Murtomäki, T. Kallio, H. J. Xu, M. Meyer, C. P. Gros, J. M. Barbe, H. H. Girault, K. Laasonen and K. Kontturi, J. Am. Chem. Soc., 2012, 134, 5974-5984.

12 P. Peljo, T. Rauhala, L. Murtomäki, T. Kallio and K. Kontturi, Int. J. Hydrogen Energy, 2011, 36, 10033-10043.

13 H. Deng, P. Peljo, F. Cortés-Salazar, P. Ge, K. Kontturi and H. H. Girault, J. Electroanal. Chem., 2012, 681, 16-23.

14 V. J. Cunnane, G. Geblewicz and D. J. Schiffrin, Electrochim. Acta, 1995, 40, 3005-3014.

15 I. Hatay, B. Su, F. Li, M. A. Méndez, T. Khoury, C. P. Gros, J. M. Barbe, M. Ersoz, Z. Samec and H. H. Girault, J. Am. Chem. Soc., 2009, 131, 13453-13459.

16 I. Hatay, B. Su, M. A. Méndez, C. Corminboeuf, T. Khoury, C. P. Gros, M. Bourdillon, M. Meyer, J. M. Barbe, M. Ersoz, S. Záliŝ, Z. Samec and H. H. Girault, J. Am. Chem. Soc., 2010, 132, 13733-13741.

17 S. Rastgar, H. Deng, F. Cortés-Salazar, M. D. Scanlon, M. Pribil, V. Amstutz, A. A. Karyakin, S. Shahrokhian and H. H. Girault, ChemElectroChem, 2014, 1, 59-63.

18 J. Jedraszko, W. Nogala, W. Adamiak, E. Rozniecka, I. LubarskaRadziejewska, H. H. Girault and M. Opallo, J. Phys. Chem. C, 2013, 117, 20681-20688.

19 I. Hatay, B. Su, F. Li, R. Partovi-Nia, H. Vrubel, X. Hu, M. Ersoz and H. H. Girault, Angew. Chem., Int. Ed., 2009, 48, 5139-5142.

20 M. D. Scanlon, X. Bian, H. Vrubel, V. Amstutz, K. Schenk, X. Hu, B. Liu and H. H. Girault, Phys. Chem. Chem. Phys., 2013, 15, 2847-2857.

21 P. Ge, M. D. Scanlon, P. Peljo, X. Bian, H. Vubrel, A. O'Neill, J. N. Coleman, M. Cantoni, X. Hu, K. Kontturi, B. Liu and H. H. Girault, Chem. Commun., 2012, 48, 6484-6486.
22 X. Bian, M. D. Scanlon, S. Wang, L. Liao, Y. Tang, B. Liu and H. H. Girault, Chem. Sci., 2013, 4, 3432-3441.

23 M. A. Mendez, R. Partovi-Nia, I. Hatay, B. Su, P. Ge, A. Olaya, N. Younan, M. Hojeij and H. H. Girault, Phys. Chem. Chem. Phys., 2010, 12, 15163-15171.

24 A. J. Olaya, M. A. Méndez, F. Cortes-Salazar and H. H. Girault, J. Electroanal. Chem., 2010, 644, 60-66.

25 B. Su, I. Hatay, F. Li, R. Partovi-Nia, M. A. Méndez, Z. Samec, M. Ersoz and H. H. Girault, J. Electroanal. Chem., 2010, 639, 102-108.

26 I. Hatay Patir, J. Electroanal. Chem., 2012, 685, 28-32.

27 A. Trojánek, J. Langmaier, B. Su, H. H. Girault and Z. Samec, Electrochem. Commun., 2009, 11, 1940-1943.

28 B. Su, R. P. Nia, F. Li, M. Hojeij, M. Prudent, C. Corminboeuf, Z. Samec and H. H. Girault, Angew. Chem., Int. Ed., 2008, 47, 4675-4678.

29 V. M. Fomin, A. A. Terekhina and K. S. Zaitseva, Russ. J. Gen. Chem., 2013, 83, 2324-2330.

30 W. M. Haynes, CRC Handbook of Chemistry and Physics, 94th ed. Internet version, CRC Press, Boca Raton, 2014.

31 B. Su, I. Hatay, P. Y. Ge, M. Mendez, C. Corminboeuf, Z. Samec, M. Ersoz and H. H. Girault, Chem. Commun., 2010, 46, 2918-2919.

32 A. Trojánek, J. Langmaier, S. Záliš and Z. Samec, Electrochim. Acta, 2013, 110, 816-821.

33 A. Trojánek, J. Langmaier and Z. Samec, Electrochim. Acta, 2012, 82, 457-462.

34 P. Sun, F. O. Laforge and M. V. Mirkin, J. Am. Chem. Soc., 2007, 129, 12410-12411.

35 D. Rose and I. Benjamin, J. Phys. Chem. B, 2009, 113, 9296-9303.

36 W. Murakami, K. Eda, M. Yamamoto and T. Osakai, J. Electroanal. Chem., 2013, 704, 38-43.

37 P. Peljo, L. Qiao, L. Murtomäki, C. Johans, H. H. Girault and K. Kontturi, ChemPhysChem, 2013, 14, 311-314. 